CORNELIA M. CLAPP.

THE following observations were made during the summer of 1891, while studying, under the direction of Dr. C. O. Whitman, at the Marine Biological Laboratory, Wood's Holl, Mass.

\title{
The Blastopore.
}

In examining the younger embryos of Batrachus tau, my attention was attracted to the appearance of the blastoderm, as seen in Fig. I. c. The egg was placed in weak osmic acid, for a few moments, when the outline could be clearly seen through the egg membrane.

Earlier stages were obtained, and treated in the same manner.

Fig. I. $a$, represents the blastoderm at the time of the first appearance of the axial thickening.

Fig. I. $b$, shows the embryonic ring when the embryo is well defined, and a little after the time when the notch first makes its appearance.

The point of special interest to be noticed, in these early stages, is the form of the blastopore, and its closure at some distance behind the embryo.

In Fig. I. $c$, the two sides of the embryonic ring are seen to approach each other, as they grow over the yolk, forming an acute angle behind the embryo, and giving rise to a very conspicuous notch.

In Fig. I. $d$, this notch is seen at a little distance behind the embryo; a shadowy connection may be traced between the germ ring and the embryo.

In later stages, this notch is seen to retreat farther behincl the embryo, as the thickened margins of the blastoderm unite, and it disappears shortly before the completion of the closure of the blastopore. 

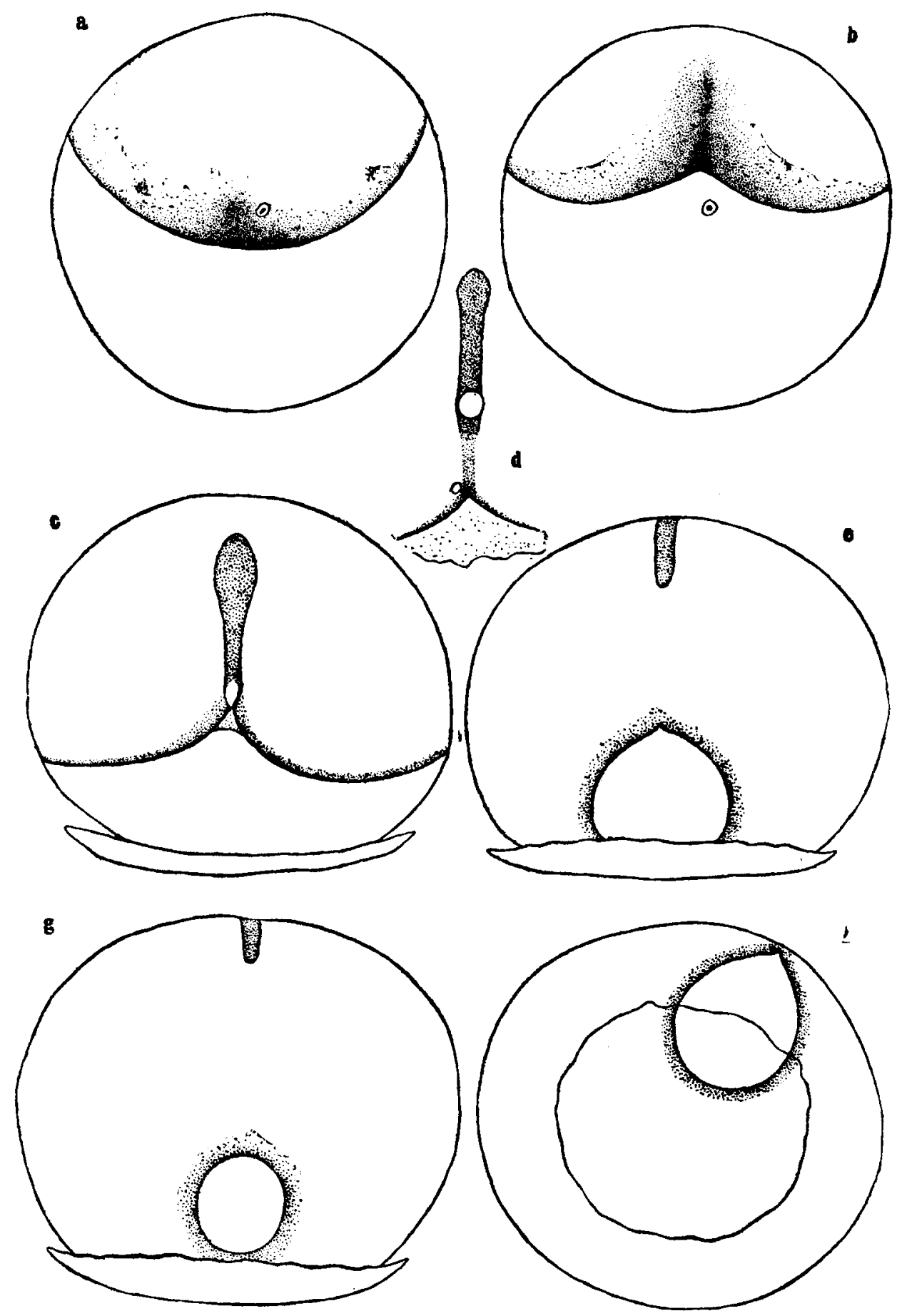

Fic. I. 
In "A Preliminary Notice of the Development of the Toadfish," ${ }^{1}$ Dr. Ryder gives a figure of the embryo in about the same stage of development as seen in Fig. I. $c$. The peculiarity in the growth of the blastoderm over the yolk seems to have been overlooked, for the embryo is represented, as in the ordinary teleost, developing at the margin of the blastoderm.

There is a striking resemblance between the appearance of the blastoderm in Fig. I. $c$, and Balfour's diagram of the Elasmobranch type of development, ${ }^{2}$ and also great similarity between Fig. I. $e$ and $g$, and Figs. I and 2, Pl. VIII., of Balfour's "Elasmo. branch Fishes."

The egg of Batrachus is enormous, as compared with that of the pelagic fish egg, being about $5 \mathrm{~mm}$. in diameter, and also larger than the egg of most amphibians, owing to the accumulation of food yolk. In this respect there is an approximation to the condition seen in the Elasmobranch egg, and to this must be attributed the peculiarities of the blastopore.

In comparing Fig. I. $e$ and $g$, with Balfour's figures of Pristiurus, before mentioned, the following points may be noticed:-

In the case of Pristiurus, at the time when about two-thirds of the yolk has been enveloped by the blastoderm, we find the embryo folded off from the yolk, and connected with it by a narrow umbilical cord, the embryo being still at the edge of the blastoderm, and the tail extending beyond it.

At a later stage, but before the closure of the blastopore, the circulation of the yolk sack is well established, and a venous trunk occupies the position of the linear streak which marks the line of coalescence behind the embryo. Fig. I. $e$ and $g$, shows the same form and position of the blastopore in Batrachus as seen in Pristiurus; but, on examination, it is found that the caudal portion of the embryo is not free from the yolk, at the time of the closure of the blastopore, neither are there any bloodvessels in the yolk sack.

In Batrachus we find a teleost exhibiting one of the interesting features of the Elasmobranch type of development, the closure of the blastopore being evidently delayed, in consequence of the great amount of food yolk, and giving rise to the yolk blastopore, which Balfour describes as "the anterior and ventral portion of the primitive blastopore."

1 Bull. of U. S. F. C., 1886.

2 Comp. Em., II. p. 126. 
A notched blastopore, at a distance behind the embryo, has hitherto been unknown among teleosts.

In rare cases a notch has been observed at the posterior end of the embryo, in transitory stages of pelagic fish eggs. In such cases the caudal lobe is divided as in Elasmobranch embryos. Two instances have been reported by Agassiz and Whitman, and one by Kingsley and Conn. Although due to the same processes of growth, this notch cannot be the same as that seen in the egg of the Elasmobranch or Batrachus.

It should be mentioned that the germ ring is remarkably narrow as compared with that of other teleosts, especially pelagic forms. This is due, probably, to the extension of the germ ring over a larger yolk sphere.

In Fig. I. $c$, the position of Kupffer's vesicle is unusual. When first seen, it lies at the extreme posterior end of the embryo, at the notch of the blastopore. In a later stage, Fig. I. $d$, this vesicle is seen to lie a little in front of the hind end of the embryo. It seems probable that the embryo has lengthened somewhat backward.

It is interesting in this connection to refer to some rare appearances in the blastoderm of the chick. A marginal notch in the blastoderm has been observed by Pander, Balfour, His, Rauber, and others, while the extension of the primitive groove through the area opaca to this notch has been seen by Dr. Whitman and Dr. Böhm. ${ }^{1}$

In comparing the Elasmobranch and Avian embryos, Dr. Whitman ${ }^{2}$ says: "In the exceptional form of blastoderm which I have described, the streak connecting the primitive groove with the marginal notch may be considered analogous to the linear streak of the Elasmobranch, while the marginal notch corresponds to the anterior angle of the yolk blastopore."

These exceptional forms scem to point to the same fundamental principle of embryonic formation in Elasmobranchs and Aves.

\footnotetext{
1 Archiv fur Anat. und Phys., 1884, p. 14. Dr. T. H. Morgan has informed me that he also has observed the notch and the extension backwards of the primitive groove to it in the chick.
}

${ }^{2}$ Quart. Four. Mic. Sci., Vol. XXI1I. New series, 1883. 


\section{Relation of the Axis of the Embryo to the First Cleavage Planes.}

The question of the coincidence of the first or second plane of cleavage with the axis of the embryo is one that has attracted considerable interest of late. As the egg of Batrachus offers unusually favorable conditions for deciding this question, I have undertaken some experiments expressly for this purpose.

It is well known that the eggs of Batrachus are adhesive. They may be found attached to the under side of boards or stones, or to the inside of tin cans, in the shallow water of the bays or inlets along the coast. A cavity is often excavated beneath a large stone by the parent fish, and the eggs deposited on the roof of this cavity.

The adhesive disk, as represented in Fig. I. $f$, is about $3 \mathrm{~mm}$. in diameter. It is a transparent thickening on one pole of the egg membrane, at the time of oviposition, and by means of it the egg is glued firmly to the rock.

The blastoderm develops at the free pole of the egg, as seen in Fig. I. $a$ and $b$, so that the first stages of cleavage can.easily be seen with a lens through the egg membrane.

On the $22 \mathrm{~d}$ of June eggs were artificially fertilized.

Having chloroformed the fish, the abdomen of the female was opened, and the ovaries cut so as to allow the mature eggs to fall and fasten themselves to the bottom of shallow glass dishes. The testes of the male were removed, and after being cut into fragments, were placed in the dishes with the eggs. Soon after this the eggs were supplied with fresh sea-water and left to develop. The adhesion of the yolk to the egg membrane, as it rested on the disk area, prevented rotation.

The first line of cleavage appeared seven hours after fertilization, and on the seventh day the axis of the embryo could be distinctly seen as a light streak in the blastoderm.

The method of determining the relation of the first cleavage planes to the axis of the embryo was as follows :-

The exact position of each egg was represented by circles on paper, and the paper and the dish containing the eggs were oriented by fastening a label on each in the same relative position. When the first line of cleavage appeared, the direction was indicated in the circle representing that egg, by the diam- 
eter, and when the axis of the embryo was visible, that was indicated by an arrow drawn across the same circle.

The result of this experiment is seen by an examination of the circles given in Fig. II. Of the twenty-three developing embryos, three show coincidence of the axis of the embryo with the first cleavage plane (Fig. II. $1,2,3$ ). There is no case of
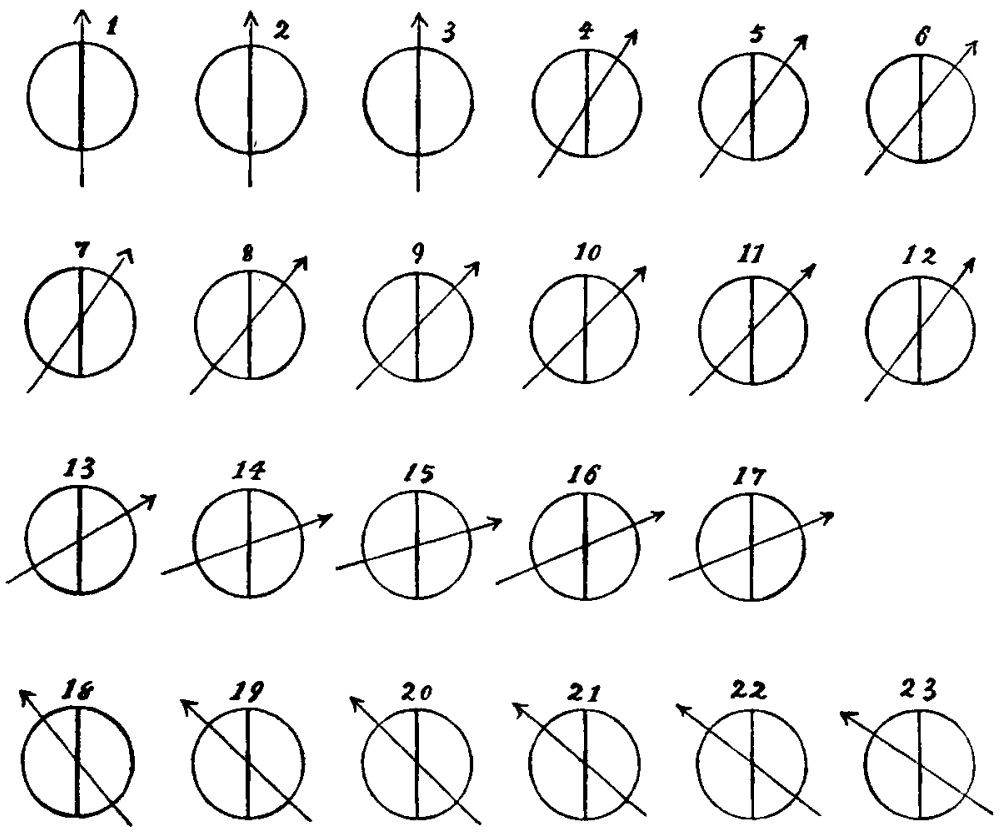

FIG. II.

exact coincidence with the second cleavage plane. Fourteen of the embryos have the head directed towards the right of the first line of cleavage, the axis of the body being at an angle with the first cleavage plane of from $30^{\circ}$ to $70^{\circ}$. In the remaining six the head was to the left of the first cleavage plane, the angle varying as before.

\section{Stages of Cleavage.}

Dr. Brooks ${ }^{1}$ has described a segmenting fish egg, which he says is probably that of Batrachus tau. He does not figure the two- or four-cell stages, but the arrangement of the cells 
in the eight-cell stage differs considerably from what I have observed.

Fig. III. 4-6 have been introduced mainly for the purpose of showing peculiarities of the eight-cell stage not shown by the figures given by Dr. Brooks. The two- and four-cell stages are much the same as in other fish eggs. In passing to the eightcell stage, the four cells elongate at right angles to the first plane of cleavage, and the two planes of the third cleavage divide these cells unequally, the four central cells being small, while the end cells are much larger (Fig. III. 4-6).
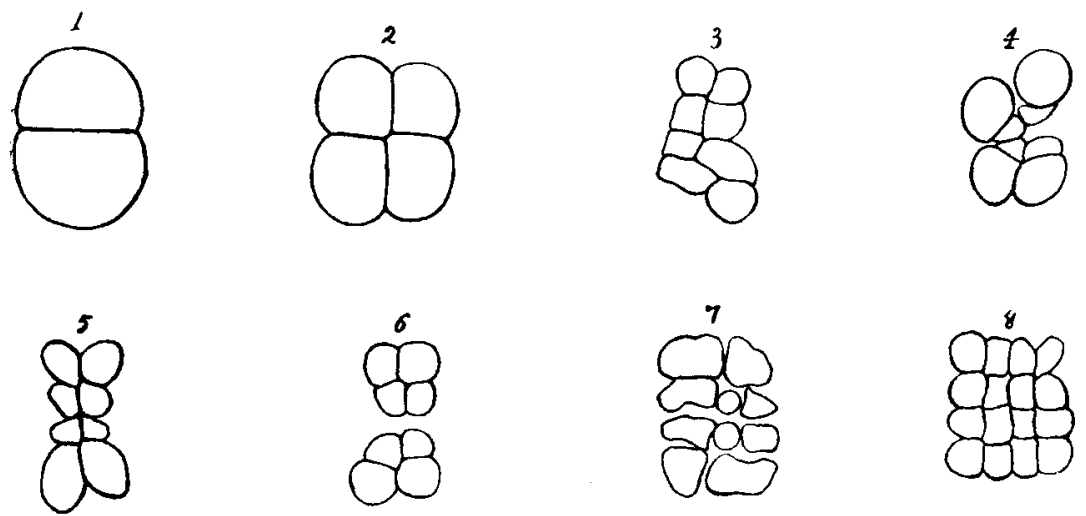

FIG. III.

The bilateral symmetry is perfect with reference to either the first or second line of cleavage, and it is so well marked in these cases that it suggests the coincidence of the axis of the embryo with the first cleavage plane.

Fig. III. 3 is somewhat asymmetrical, while Fig. III. 8 shows a remarkably symmetrical sixteen-cell stage. Fig. III. 7 shows that stage in process of cleavage.

\section{Position of Adherent Embryos.}

In the paper referred to above, Dr. Ryder describes the young adherent embryos as having their heads invariably directed towards the opening of their retreat, and adds: "It would seem that the direction from which the light comes has a great deal to do in determining the direction of the axis of the body of the future embryo." 
A different explanation of this fact is given by Dr. Ryder in a recent paper." $\mathrm{He}$ says: "The future axis of the whole brood of embryos was predetermined in the body of the parent."

It was observed during the past summer that the embryos within the egg membrane do not have their heads all turned the same way, but in every possible direction, and it is only after the young toad-fish are hatched that the heads of the whole brood are turned in the same direction.

During the larval period the yolk sack is attached to the inside of the egg membrane, and the possibility is suggested that the turning toward the light is effected at the time of hatching, when, according to Dr. Ryder, the attachment of the yolk sack may take place.

1 Proc. of Am. Phil. Soc., Vol. XXVIII., p. 14I. 